\title{
INDIGENOUS CONSERVATION OF CROP GENETIC RESOURCES IN THE UPPER EAST REGION OF GHANA
}

\author{
Essel $^{1 *}$, E., Galley 1 , J. J., Mohammad ${ }^{1}$, H. D., Imoro ${ }^{1}$, A-W. M., Sackey², I. \& Adonadaga ${ }^{3}$, M. \\ ${ }^{1}$ Department of Applied Biology, C.K. Tedam University of Technology and Applied Sciences, Navrongo, Ghana. \\ ${ }^{2}$ Department of Biological Sciences, University for Development Studies, Tamale, Ghana \\ ${ }^{3}$ Department of Environmental Science, C.K. Tedam University of Technology and Applied Sciences, Navrongo, Ghana. \\ *Corresponding author: Email: afariwae@yahoo.com
}

\begin{abstract}
Traditional farmers are aware of crop genetic erosion and use various indigenous conservation methods in their farming systems to protect and sustain crop production. The objective of the study was to assess the indigenous conservation methods and practices for some selected crop genetic resources (CGRs) in the Kassena-Nankana and Bolgatanga areas of Ghana. Data was gathered with the aid of a questionnaire, secondary data and first-hand observations. The primary subject for the study were farmers. The study communities were selected by convenient sampling and based on key informants' information. Two hundred farmers from ten communities each from Kassena-Nankana and Bolgatanga municipalities served as subjects in this study. The results revealed that, farmer's choice of CGRs for cultivation was based on food preference, marketability, and early maturing crops among others. Maize, millet, rice and groundnut were the most cultivated crops in the two study areas making up 15-25\%. In both areas, 52-65\% of the farmers were males and 35-48\% females. Use of preserved seeds as planting materials was practiced by 41-49\% of farmers, 21-26\% purchased their planting materials and 21-23\% practiced a combination of the two. The indigenous conservation practices were pot preservation, bunch hanging, bottle preservation, sack preservation and local silos/barns. Methods employed to achieve CGRs conservation included the use of ashes from burnt plant residue and plant parts and plant extracts. The findings of the study revealed that some indigenous practices are moderately practiced by the farmers in the surveyed areas to ensure CGRs conservation and food security.
\end{abstract}

\section{Keywords: Conservation practices, Crop, Genetic resources, Farmers, Indigenous, Ghana}

\section{Introduction}

Plant genetic resource refers to plant material that has economic or utilitarian value whether current or future, and the most important being that it contributes to food security (IBPGR, 1991). Concerns about erosion of crop genetic resources (CGRs) were first articulated by scientists in the mid- $20^{\text {th }}$ century and have since become an important part of national policies and international treaties (Gepts, 2006). Effective conservation and utilization of plant genetic resources, improving environmental conditions and sustainable development of agriculture are important for food security and feeding the ever-increasing world population (FAO, 2010). Therefore, there is an awareness globally of the need to conserve valuable CGRs 
for the immediate benefit of the present generation as well as for the long term (FAO, 2010).

Much of the world's biological diversities of plants are in the custody of farmers who follow age-old farming and preservation practices (Oldfield \& Alcom, 1991). Indigenous preservation of plant genetic resources with various locally made materials is, therefore an old practice among many farming communities of developing countries (Oldfield \& Alcom, 1991). These materials are designed to prevent the invasion of crop pests and destruction by unfavorable weather conditions. Preservation of seeds in gourds, cylindrical pits dug in earth or granaries or in containers made of ropes and plastered with mud and cow dung, baked clay pots, plastic bags, plastic drums and glass bottles to prevent disease, animals and pest destruction have been reported (Ayamdoo, Demuyakor, Badii \& Sowley, 2013). Clay pots were claimed to have high storage capacities, insect resistant and durable though they were more expensive and less portable however, the women mostly preferred to store their seed in pots (Kudadjie \& Dankyi, 2012). Jute sacks have also been found to be more portable with high storage capacities but not insect-proof or moisture-resistant. (Ayamdoo et al, 2013).

The world's poorest people are at risk of increased hunger, particularly those in the tropical and subtropical areas in the face of climatic change, pest and diseases that affect agriculture (IPCC, 1996), with the potential impact of widespread crop and yield losses (Ogwu, Osawaru. \& Ahana, 2014). Preservation of plant genetic resource serves as a way of conservation of biodiversity and reduces the incidence of genetic vulnerability (van Zonneveld, Kindt, Solberg, N'Danikou \& Dawson, 2021). Thus, the objective of the study was to assess and document indigenous conservation methods and practices for selected crop genetic resources (CGRs) in the KassenaNankana and Bolgatanga areas of Ghana.

\section{Methods}

\section{Study area and sample size descriptions}

The study was conducted in 2015 and the selected areas for the study were Bolgatanga (Bolga) and Kassena-Nankana municipalities $\left(10^{\circ} 15^{\prime} \mathrm{N}\right.$ and $11^{\circ} 10^{\circ} \mathrm{N}, 1^{0} 30^{\prime} \mathrm{W}$, altitude 200 $400 \mathrm{~m}$ above sea level) in the Upper East Region of Ghana. Twenty (20) farming communities were conveniently sampled based on key informants' information for the study and ten (10) randomly selected farmer respondents from each community including key informants were interviewed, giving a sample size of two hundred (200). The Kassena-Nankana area study communities included Vunania, Gaani, Pungu, Nayagnia, Doba, Tono, Gonia, Bonia, Bundunia and Apiita (Fig 1B). The Bolgatanga area study communities included Vea, Sumbrugu, Abempigo A and B, Kalbeo, Kumbangre, Zuarungu, Tindosobligo, Nyariga and Gabiisi (Fig 1B). 

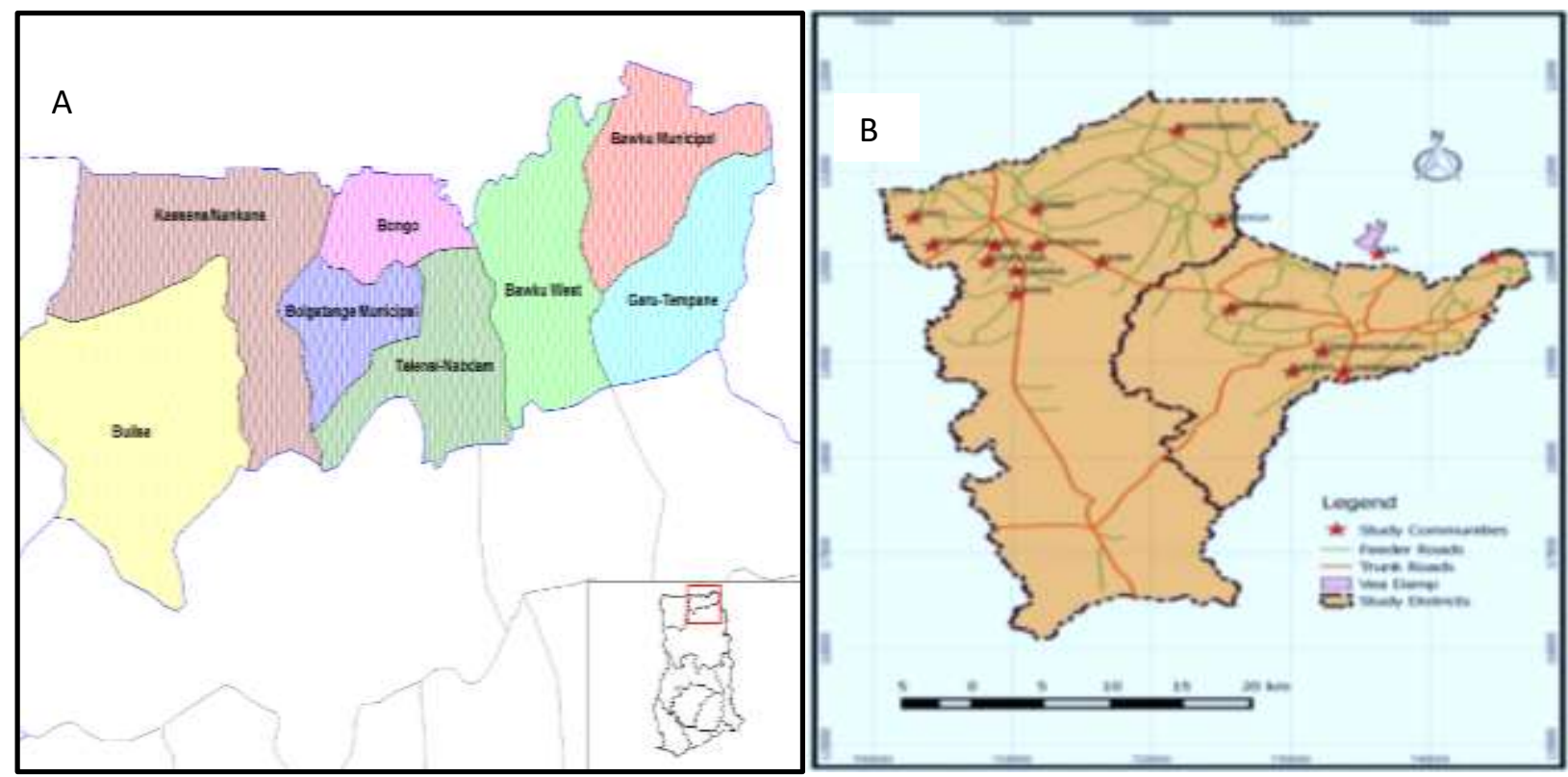

Fig 1 Maps of the Upper East Region of Ghana (A) and study communities in the Bolgatanga and Kassena-Nankana areas (B). Source of map A, Ghana Statistical Service Report (2013).

\section{Data Collection Procedure}

Primary data was generated by using structured questionnaire with both closed and open-ended questions to collect information from farmers. The inclusion criterion was that the respondent should be involved in farming for at least the last five (5) years. Reconnaissance visits were first made to the farmers' houses in all the twenty communities with the assistance of Assembly members and key informants and given identification tags. In each community, all the identification tags were written separately on pieces of paper, folded and mixed up meticulously. Then one was picked at random without replacement until ten pieces were obtained. These represented the houses whose farmers were to be involved in the survey. Then, in each house visited only one farmer was interviewed by using a questionnaire. Thus, a simple random sampling was used to select the participants from the twenty (20) communities in this study. In each community, ten (10) randomly selected farmer respondents were involved and each farmer was administered a questionnaire using the direct interview method. Also, personal observation and photographs of structures and practices were captured to document the indigenous preservation methods for crop genetic resources (CGRs) in the study areas. Secondary data was obtained from the local Ministry of Food and Agriculture office in the study areas which provided information on the various indigenous practices for crop genetic resource preservation among others to verify the primary data obtained.

\section{Data Analysis}

Data analysis was performed with the Statistical Package for Social Sciences version 19.0 (IBM Corp., Chicago, IL, USA) with the categorical and continuous variables tabulated and presented with their corresponding percentages. 


\section{Results}

\section{Respondents' profile}

Both men and women were included in the survey and males were $52 \%$ and $48 \%$ were female respondents in the Kassena-Nankana area (Table 1). In the Bolgatanga area, 65\% were males and $35 \%$ were female respondents. The ages of both sexes ranged from 15-100 years, farm sizes ranged from 0.5 to 20 acres and $43 \%$ of respondents lacked formal education (Table 1).

Table 1 Respondent farmer profile in the study communities in the Bolgatanga and Kassena-Nankana areas.

\begin{tabular}{|c|c|c|c|}
\hline & \multirow[t]{2}{*}{ Responses } & \multicolumn{2}{|c|}{ Percentage (\%) } \\
\hline & & Bolgatanga & Kassena-Nankana \\
\hline \multirow[t]{2}{*}{ Sex } & Male & 65 & 52 \\
\hline & Female & 35 & 48 \\
\hline \multirow{2}{*}{ Marital status } & Single & 9 & 19 \\
\hline & Married & 91 & 81 \\
\hline \multirow{6}{*}{ Age (years) } & $15-24$ & 6 & 11 \\
\hline & $25-34$ & 17 & 21 \\
\hline & $35-54$ & 56 & 37 \\
\hline & $55-74$ & 9 & 19 \\
\hline & $75-100$ & 0 & 3 \\
\hline & Do not know & 18 & 9 \\
\hline \multirow{5}{*}{ Educational level } & Basic & 24 & 19 \\
\hline & Secondary & 23 & 17 \\
\hline & Tertiary & 7 & 14 \\
\hline & None & 43 & 46 \\
\hline & Others & 3 & 4 \\
\hline \multirow{4}{*}{ Occupation } & Teaching & 26 & 12 \\
\hline & Trading & 8 & 15 \\
\hline & Farming & 49 & 58 \\
\hline & Others & 15 & 15 \\
\hline \multirow{6}{*}{ Farm size in acre(s) } & $0.5-1$ & 23 & 24 \\
\hline & $2-5$ & 46 & 57 \\
\hline & $6-10$ & 21 & 14 \\
\hline & $11-15$ & 5 & 1 \\
\hline & $16-20$ & 1 & 0 \\
\hline & Do not know & 4 & 4 \\
\hline
\end{tabular}

Source: Field data, May, 2015

\section{Types of crop genetic resource cultivated}

Maize, millet, rice and groundnut were cultivated by 15 to $24.8 \%$ and 17 to $24 \%$ of farmers in the Kassena-Nankana and Bolgatanga areas, respectively (Fig 2). Other crops such as sorghum, tomatoes, pepper and beans were also cultivated by 1.6 to $7.8 \%$ of farmers in the two areas (Fig 2). The most common reason given by respondents for cultivating the selected crops was influenced by their utilization as staple food (44 and 56\%) and marketability and income generation (21 and 26\%) in the study areas (Table 2). Early maturing crops were preferred by the farmers (35 and 33\%). Majority of farmers (59 and 60\%) could not give the reasons for their preference for the crops selected. However, 
a few farmers (7 to $22 \%$ ) mentioned income and marketability, domestic use and climatic suitability as their reasons for preference (Table 2).

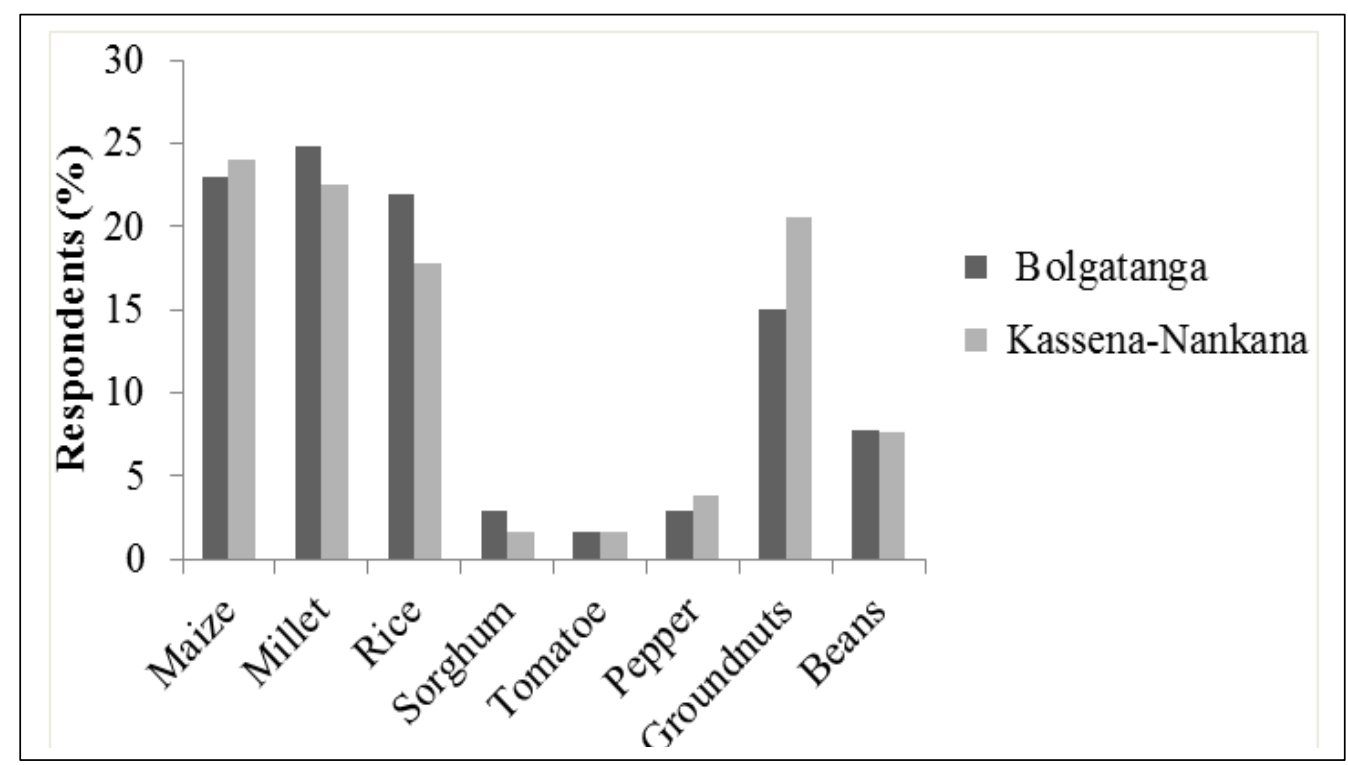

Source: Field data, May, 2015

Fig 2 Crops cultivated in the study communities in the Bolgatanga and Kassena-Nankana areas.

Table 2 Reasons for farmer choice of crop cultivated.

\begin{tabular}{|llcc|}
\hline & Responses & Bolgatanga (\%) & Kassena-Nankana (\%) \\
\hline \multirow{3}{*}{ Reasons for cultivating } & Staple food & 56 & 44 \\
the selected crops & Soil type and fertility & 11 & 16 \\
& Early maturing & 6 & 9 \\
& Income and marketability & 21 & 26 \\
& Water requirement for growth & 6 & 5 \\
\hline \multirow{3}{*}{ Types of crops preferred } & Late maturing crops & 9 & 8 \\
& Early maturing crops & 35 & 33 \\
& No answer & 56 & 59 \\
\hline \multirow{3}{*}{ Reasons for preference } & Income and marketability & 18 & 22 \\
& Domestic use & 17 & 12 \\
& Climatic suitability & 5 & 7 \\
& No answers & 60 & 59 \\
\hline
\end{tabular}

Source: Field data, May, 2015

\section{Sources of CGRs cultivated and reasons for purchasing or preserving}

In both areas of Bolgatanga and KassenaNankana, 49 and $41 \%$, respectively resorted to the practice of preserving selected CGRs from the previously harvested stock whereas 26 and $21 \%$ of the farmers in the two areas, respectively purchased seeds from the seed market, either being the improved variety or the indigenous variety (Fig 3). Preserving selected CGRs from the previously harvested stock and purchasing from the market were practiced by 21 and $34 \%$ in the two study areas whereas $4 \%$ of respondents in both study areas gave other 
sources of their CGRs for cultivation (Fig 3). The inability to preserve CGRs was reported by 12 and $17 \%$ of respondent farmers in the Bolgatanga and Kassena-Nankana areas, respectively resorting to purchasing (Fig 3). Insufficient quantity of the preserved seeds (sometimes) was the reason for 17 and $26 \%$ of respondents in the two study areas purchasing CGRs, especially when they want to expand their farms. Preference for early maturing varieties by 20 and $13 \%$ of respondent farmers in the Bolgatanga and Kassena-Nankana areas, respectively was the reason for buying improved varieties (Fig 3). According to the results, 32 and $18 \%$ of farmers from the Kassena-Nankana and Bolgatanga areas, respectively said they preserve because it is a cultural heritage and the only alternative available to get good CGRs for cultivation since the viability of those from the local market is not dependable (Fig 3). Also, between 20 to $24 \%$ of respondents from the two study areas indicated that preserving their own CGRs for cultivation is dependable and cheaper, considering that they do not have enough capital to purchase seeds. Also, 4 and $2 \%$ of respondent farmers from the Kassena-Nankana and Bolgatanga, respectively preserve because they prefer the indigenous varieties which they inherited from their descendants (Fig 3). However, 35 and $18 \%$ of respondents from the two study areas, respectively either did not preserve or had no clear reason for preservation.

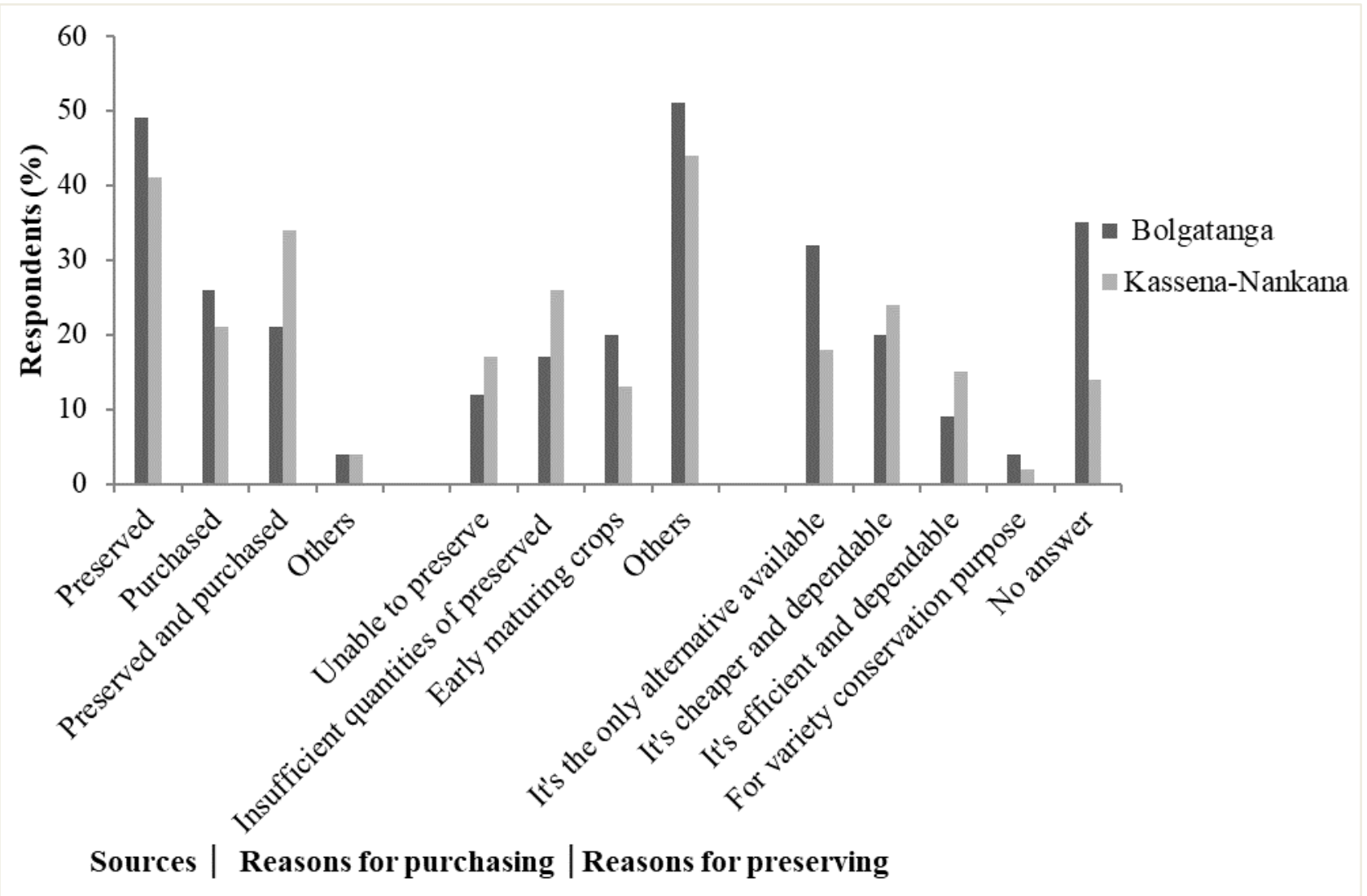

Source: Field data, May, 2015.

Fig 3 Sources of crop genetic resource for cultivation and reasons for purchasing or preserving.

Indigenous practices, methods used and challenges associated with CGRs preservation

The materials and methods used in preserving CGRs were almost the same in each community visited in the study areas. Of the respondents interviewed, $13 \%$ in both areas practiced pot preservation (Fig 4) 
and this method was widely used in the preservation of a variety of CGRs including millet, maize, beans, rice, sorghum groundnuts and pepper. Also, 5 and $4 \%$ of respondents, respectively in both areas practiced bunch hanging and this method was widely used in preserving maize and sometimes rice, sorghum and millet. Out of the respondents interviewed, 5 and 12.4\% of farmers in Bolgatanga and Kassena-Nankana, respectively practiced bottle preservation and this method was used for vegetable seed preservation including pepper and tomato seeds after being washed. Sack preservation was the most widely used preservation method practiced in the two areas making up to 55 and $40 \%$ in the two study areas, respectively and this method is said to be suitable for the preservation of cereals (Fig 4). Local silos or barn preservation was the second most commonly used preservation method being reported by 20 and $31 \%$ of farmer respondents in the two study areas, respectively (Fig 4, 5A). The local silos or barn method was said to be suitable for cereals and legumes.

Ashes from burnt plant residues were used by 35\% of farmers in Bolgatanga and 31\% in KassenaNankana to store and preserve CGRs (Fig 4). In both study areas, 19.6 and 15.4\% respectively used plant parts and plant extracts for preservation. Fumigants and insecticides were used by 5.7 and $53.8 \%$ of respondent farmers in Bolgatanga and Kassena-Nankana areas respectively for CGRs preservation (Fig 4). Respondent farmers who used fumigants, insecticides and other synthetic chemicals reported that they did so with caution since some are poisonous and detrimental to human health. Others said they used slightly washed weedicide containers to store vegetable seeds and some cereals for future planting. Among the challenges associated with CGRs preservation in the two study areas, pest and moisture spoilage was reported by 5 and $6 \%$ of respondent farmers in Bolgatanga and Kassena-Nankana areas, respectively (Fig 4). Pest and rodent spoilage was reported by 30 and $46 \%$ of respondent farmers whereas moisture spoilage was reported by 5 and $6 \%$ in the two study areas. Other respondent farmers (31 and 27\%) in the two study areas reported no challenges while 29 and $15 \%$ could not assess the source of damages (Fig 4).

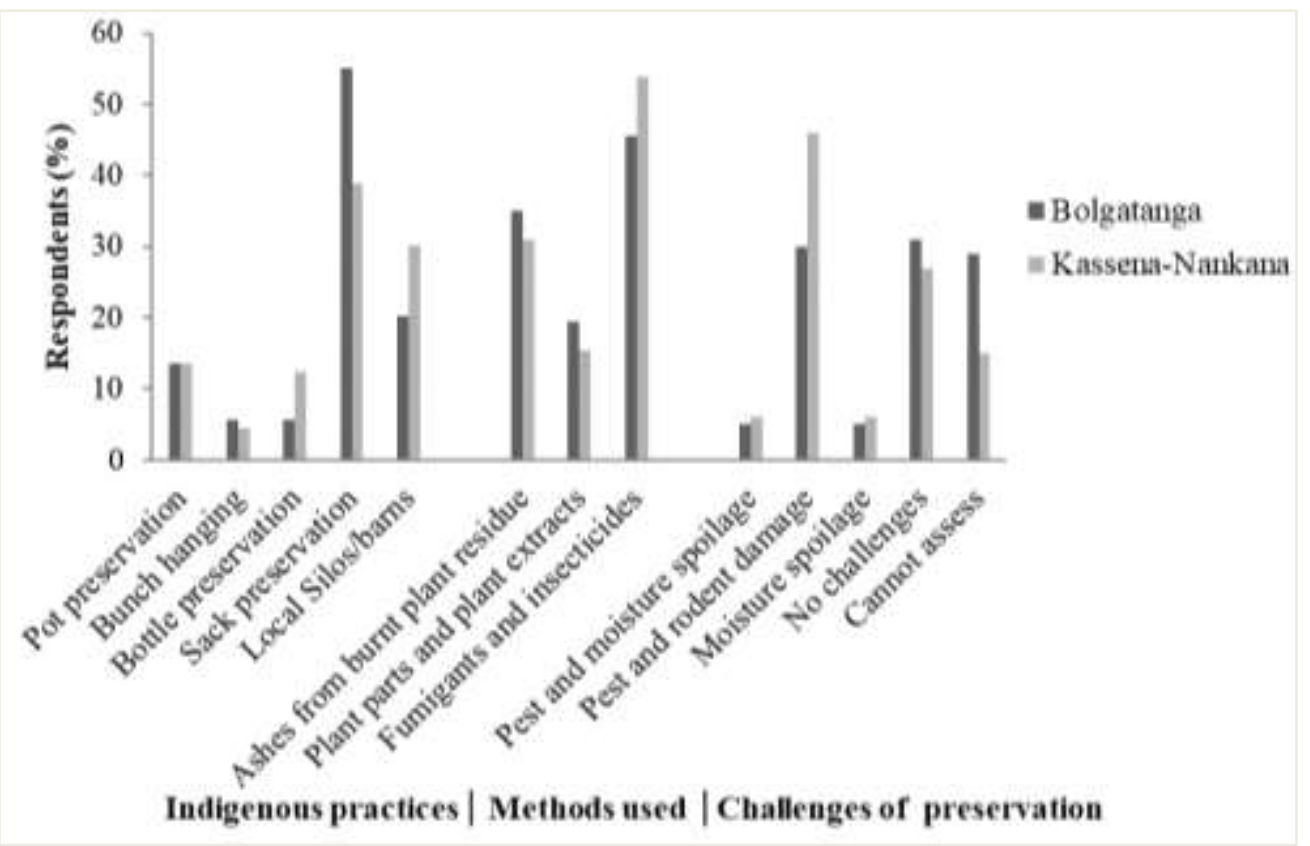

Source: Field data, May, 2015

Fig 4 Indigenous practices, methods used and challenges associated with crop genetic resource preservation in the study areas. 

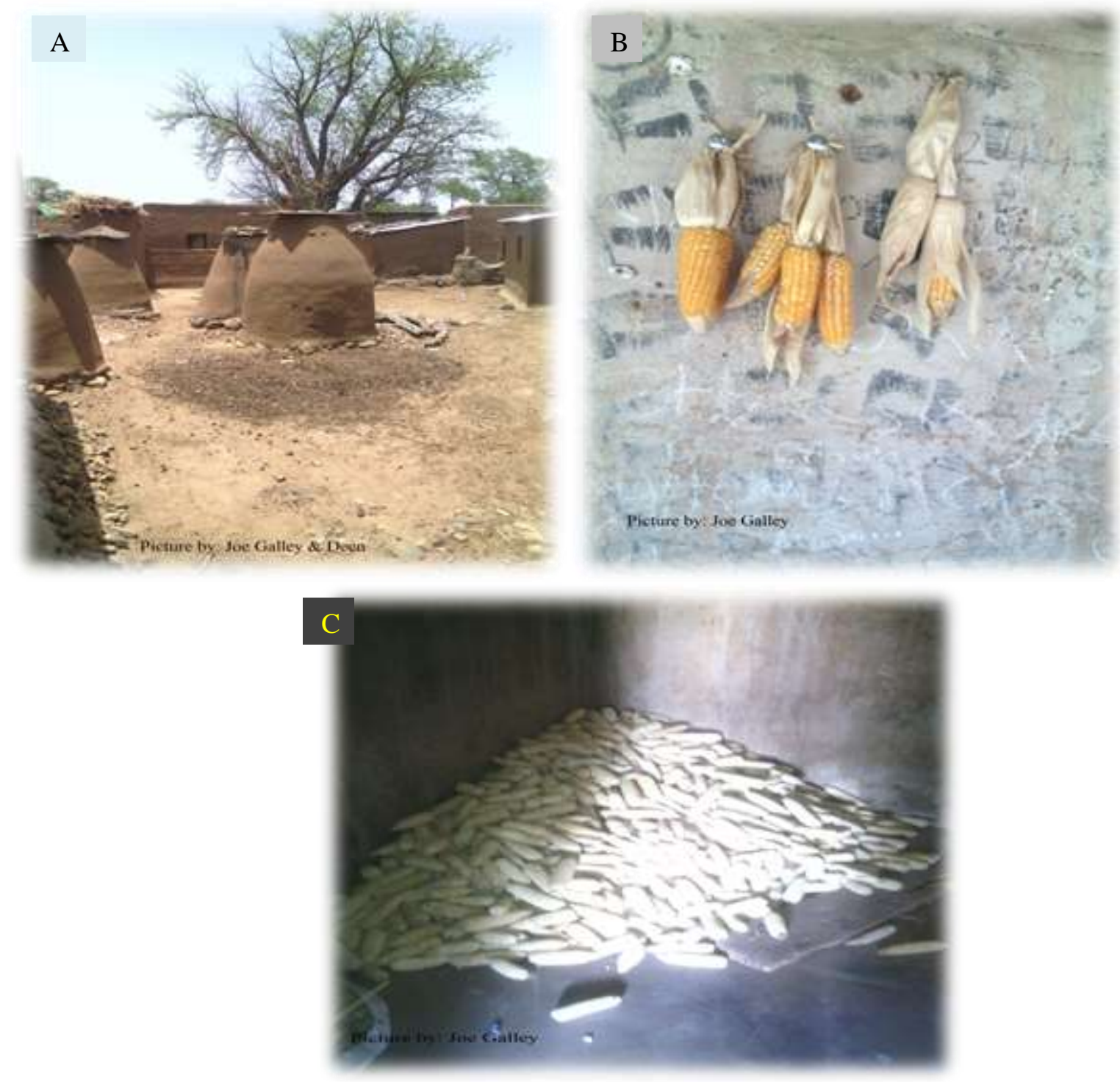

Source: Field photo, May, 2015

Fig 5 Indigenous practices and methods used to conserve crop genetic resources in some study communities.

Locally built silos/barn method of preservation at Vunania in Kassena-Nankana (A), bunch hanging of maize on wall at Kumbangre in Bolgatanga (B) and maize stored in room floor at Bonia in Kassena-Nankana area (C).

\section{Farmer knowledge on CGRs conservation}

As to whether farmers had any form of training on CGRs conservation, only 7 and $15 \%$ of respondents in Bolgatanga and Kassena-
Nankana areas, respectively said they have had such training, 93 and $85 \%$ of respondents in the two areas, respectively had no idea what CGRs conservation was about (Table 3). In both Bolgatanga and Kassena-Nankana areas, 93 and $85 \%$ of respondents respectively could not provide the name of organizations that organized the training, knowledge acquired and outcome of training. However, 2-6\% of 
respondents mentioned NGOs (NonGovernmental Organisations) and MOFA (Ministry of Food and Agriculture) as organizers of such training programmes in the communities. The knowledge acquired by the trained farmers on CGRs conservation included the selection of seeds by 1 and $8 \%$ of respondents in Bolgatanga and Kassena-Nankana areas, respectively. Results on the outcome of training showed that 3 and $10 \%$ of respondents in Bolgatanga and Kassena-Nankana areas, respectively said it was helpful and 4 and $5 \%$ of respondents in Bolgatanga and Kassena-Nankana areas, respectively could not assess the impact of the training. The study revealed that 66 and $72 \%$ of respondent farmers in Bolgatanga and KassenaNankana areas, respectively will accept an effective and more efficient alternative method of PGR preservation if taught (Table 3). The 44 and $28 \%$ of respondents in Bolgatanga and Kassena-Nankana areas, respectively who will not accept any other method explained that the method they practice was efficient while others said their method is a cultural heritage and will not compromise with it.

Table 3 Famer education and knowledge of crop genetic resources conservation.

\begin{tabular}{|llcc|}
\hline & Response & Bolgatanga (\%) & Kassena-Nankana (\%) \\
\hline Farmer training on & Yes & 7 & 15 \\
crop genetic resources & No & 93 & 85 \\
conservation & No answer & 2 & 5 \\
\hline Name of organisations & NGOs & 2 & 6 \\
that organised training & MoFA & 4 & 5 \\
program & Others & 1 & 3 \\
& Do not know & 0 & 1 \\
& No answer & 93 & 85 \\
\hline & Selection of seeds & 1 & 8 \\
& Conservation procedures & 0 & 1 \\
Knowledge acquired & Harvest methods & 1 & 1 \\
& Use of appropriate storage & & 3 \\
& materials & 3 & 2 \\
& Do not know & 2 & 85 \\
& No answer & 93 & 10 \\
& Helpful & 3 & 0 \\
Outcome of training & Not helpful & 0 & 5 \\
& Cannot assess & 4 & 85 \\
& No answer & 93 & 72 \\
Acceptance of an & Yes & 66 & 23 \\
\hline alternative method & No & 31 & 9 \\
\hline \multirow{2}{*}{ Practice of the method } & Yes & 4 & 5 \\
& No & 3 & 85 \\
\hline & No answer & 93 & 3 \\
\hline
\end{tabular}

Source: Field data, May, 2015. Note: NGOs, Non-Governmental Organisations); MoFA, Ministry of Food and Agriculture. 


\section{Discussion}

Documentation of Indigenous practices and methods of CGRs conservation

The study was aimed at documenting indigenous knowledge of CGRs conservation and preservation methods and practices. Agricultural research has often failed to achieve the required impact for many resource-poor farmers especially in Africa and this has led to low productivity and poor management of CGRs and eventually causing erosion of diversity. Accompanied with that, loss of plant genetic resources is poorly documented (Virchow, 1999), as many farmers do not know exactly which variety of CGRs in their custody are improved or indigenous since they cultivate both. The traditional methods of local farmers are as important as the methods used by modern mechanized agriculture although there has been little effort made to improve this knowledge. A study conducted by Warren (1992) in Kenya on indigenous knowledge, biodiversity conservation and development indicated that very little of this knowledge has been recorded. According to Linden (1991), much of this knowledge is at as much risk of being lost as is the case with biodiversity.

As farmers switch to more economic cultivars, cultural methods to preserve indigenous crops may no longer be useful since these improved varieties are readily available in the market. This may result in the extinction of the method/ practices and the indigenous crops that are preserved by the method causing loss of diversity. Preservation of cultural information according to Nazarea (1998), supports and complements the genetic agronomic characterization of many important crops. This goes a long way to improve crop production since indigenous knowledge of CGRs preservation varies and its complexity depends on the type of PGR being preserved. Guarino and Friis-Hansen (1995), Nazarea (1998) and Quek and Friis-Hansen (2011) gave detailed guidance on making traditional knowledge journals and on 'memory-banking', a procedure analogous to 'seed banking'.

\section{Indigenous and contemporary conservation practices of plant genetic resource}

The study revealed that there are little efforts made by farmers and the various agencies to conserve abandoned/neglected varieties of landraces. Abandoned varieties of landraces are mainly indigenous varieties of crops/landraces that are no longer cultivated due to their long duration on the field and low yielding capacity and considered non-economical especially in this part of Ghana where the wet season is short. The switch to the cultivation of genetically improved cultivars that have a much shorter duration on the field and have high yielding capacity, led to the gradual erosion of landraces (Birhanu Abegaz, \& Hailu Tessema, 2021). From the data collected on farmer knowledge and training on plant genetic resource conservation, only $7-15 \%$ of respondents in the two areas were aware or had any form of knowledge on conservation CGR especially those landraces on the verge of extinction.

The loss of plant genetic resources according to Virchow (1999) is poorly documented but it is clear that a concentration on fewer crops and cultivars can be observed. A survey conducted by Buah, Huudu, Ahiabor, Yakubu \& Abu-Juam, (2010) in the Upper West region on fifty-nine neglected sorghum landraces revealed that majority of sorghum farmers in the region were no longer cultivating the neglected sorghum varieties on a large scale. Among the farmers interviewed, very few (about 10\%) still grow the 
endangered sorghum varieties on very small plots annually. The main reasons cited by the farmers for increasingly neglecting the sorghum landraces included low productivity (56\%) moisture stress (27\%), varietal growth characteristics (10\%) and poor soils (Buah et al, 2010). Research conducted by Hammer \& Teklu, (2008) reveals that erosion of these genetic resources along with accompanying practices and knowledge that farmers use to develop, utilize and conserve crop genetic resources could pose a severe threat to the world's food security in the long term.

\section{Methods, practices and associated challenges of CGRs preservation}

The results for methods and materials used in CGRs preservation indicates that many of the farmers $(40-55 \%)$ who cultivate cereals used sacks and locally built mud silos plastered with cow dung (20-31\%) in both areas. Pest, rodent and moisture spoilage has been the major challenge farmers face in preserving CGRs. In the quest to find solutions to the pest and rodents problem farmers use various chemicals and substances some of which are poisonous and detrimental to humans and livestocks when mistakenly eaten. The use of plant parts, ash, leaves and extracts according to Ayamdoo et al (2013) are based on some scientific principles. Ash contains a level of silica that deters the egg formation of pests and larval feeding. According to the farmers, the use of Neem (Azadirachta indica) emits a pungent smell that deters pest invasion due to the presence of meliacin, nimbin, nimbinene, nimbandiol and azadiractin (Mordue et al, 2005). The use of orange peels and lemon extracts have proven to contain lemon oil, citric acid and pectin (Mahato et al, 2019; Ruano et al, 2019). All these substances found in these plant materials have been reported to be anti-feedants against several pests (Mordue et al, 2005). But the uses of these substances are reducing very fast due to the availability of synthetic fumigants and pesticides purchased from the markets which according to farmers are effective but poisonous and not environmentally friendly.

\section{Conclusion}

The study revealed that the main crops cultivated in the Bolgatanga and KassenaNankana areas included maize, millet, rice and groundnut. The use of preserved seeds from the previous season as planting materials was practiced by about $49 \%$ of farmers, almost $26 \%$ purchased their planting materials and approximately $23 \%$ practiced a combination of the two sources. The indigenous conservation practices in the study areas included pot preservation, bunch hanging, bottle preservation, sack preservation and local silos or barns. The methods used to conserve CGRs were use of ashes from burnt plant residue and plant parts and plant extracts. Therefore, we conclude that some indigenous conservation efforts are consciously made and practiced by the farmers in the study areas to promote conservation of CGRs and food security.

\section{References}

Ayamdoo, A. J., Demuyakor, B., Badii, K.B. \& Sowley, E.N.K. (2013). Storage systems for bambara groundnut (vigna subterranean) and their implications for bruchid pest management in talensinabdam district, upper east region. International Journal of Scientific \& Technology Research, 2, 182 -185. 
Birhanu Abegaz, S., \& Hailu Tessema, F. (2021). Farmers' Perception about the use of Sorghum (Sorghum bicolor (L.) Moench) landraces and their genetic erosion in South Wollo Administrative Zone, Ethiopia. International Journal of Agronomy, 2021, 3601897.

Buah, S. S. J., Huudu, A. B., Ahiabor, B. D. K., Yakubu, S. \& Abu-Juam M. (2010). Farmer Assessment, Conservation and Utilization of Endangered Sorghum Landraces in the Upper West Region of Ghana. West African Journal of Applied Ecology, 17, 11-25.

Food and Agriculture Organization (FAO). (2010). The contribution of Plant Genetic Resources for Food and Agriculture (PGRFA) to food Security and Sustainable agricultural development. In: The Second Report on the State of the World's Plant Genetic Resources for Food and Agriculture. Rome, Italy. Pp 184-185.

Gepts, P. (2006). Plant Genetic Resources Conservation and Utilization: The Accomplishments and Future of Societal Insurance Policy. Crop Science, 46, 2278-2292.

Ghana Statistical Service. (2013). 2010 Population and Housing Census Regional Analytical Report Upper East Region. Ghana Statistical Service.

Guarino, L. \& Friis-Hansen, E. (1995). Collecting plant genetic resources and documenting associated indigenous knowledge in the field: a participatory approach. In: Ramanatha Rao, V., Reid,
R. (Eds), Collecting Plant Genetic Diversity: Technical Guidelines (Pp 195-228). CAB International, Wallingford.

Hammer, K. \& Teklu, Y. (2008). Plant Genetic Resources: Selected issues from genetic erosion to genetic engineering. Journal of Agriculture and Rural Development in the Tropics and Subtropics, 109 (1), $15-50$.

Intergovernmental Panel on Climate Change (IPCC). (1996). Revised 1996 IPCC Guidelines for National Greenhouse Gas Inventories. In: Houghton, J. T., Meira Filho, L. G., Lim, B., Treanton, K., Mamaty, I., Bonduki, Y., Griggs, D. J., Callender, B. A (Eds). IPCC/OECD/IEA.UK Meteorological Office, Bracknell.

International Board for Plant Genetic Resources (IBPGR). (1991). IBPGR annual report. $65 \mathrm{pp}$.

Kudadjie, C. F. \& Boateng, S. D. (2012). Gender and Cultural Dimensions of Sorghum Seed Management in NorthEast Ghana. Global Journal of Biology, Agriculture and Health science. 1(2), 49.

Linden, E. (1991). Lost tribes, lost knowledge. Time, September 23. 138(12), 46-56.

Mahato, N., Sinha, M., Sharma, K., Koteswararao R. \& Cho, M. H. (2019). Modern Extraction and Purification Techniques for Obtaining High Purity Food-Grade Bioactive Compounds and 
Value-Added Co-Products from Citrus

Wastes. Foods, 8, 523, 81 pages

Mordue, A. J., Morgan, E. D. \& Nisbet, A. J. (2005). Azadirachtin, a natural product in insect control. In: Gilbert, L. I. (Ed), Comprehensive Molecular Insect Science (Pages 117-135). Elsevier. Amsterdam, Netherlands.

Nazarea, V. D. (1998). Cultural Memory and Biodiversity. University of Arizona Press, Tucson.

Ogwu, M. C., Osawaru, M. E. \& Ahana, C. M. (2014). Challenges in conserving and utilizing plant genetic resources (PGR). International Journal of Genetics and Molecular Biology. 6(2), 16-22.

Oldfield, M. L. \& Alcom, J. B. (1991). Biodiversity Culture Conservation and Ecodevelopment. Westview Press.

Quek, P. \& Friis-Hansen E. (2011). Collecting plant genetic resources and documenting associated indigenous knowledge in the field: a participatory approach. In: Guarino L., Ramanatha Rao V., Goldberg E. (Eds). Collecting Plant Genetic Diversity: Technical guidelines - 2011 update, Bioversity International, Rome, Italy.

Ruano, P., Delgado, L. L., Picco, S., Villegas, L., Tonelli, F., Merlo, M. E. A., Rigau, J., Diaz, D. \& Masuelli, M. (2019). Extraction and Characterization of pectins from peels of Criolla Oranges (Citrus sinensis): Experimental Reviews. IntechOpen Book Series. https://doi.org/10.5772/intechopen.8894 4

van Zonneveld, M., Kindt, R., Solberg, S. Ø., N'Danikou, S. \& Dawson, I. K. Diversity and conservation of traditional African vegetables: Priorities for action. Diversity and Distributions. 2021; 27: 216- 232.

Virchow, D. (1999). Genetic resources: Status, development, losses and conservation management. In: Conservation of Genetic Resources - costs and Implications for Sustainable Utilisation of Plant Genetic Resources for Food and Agriculture. Berlin, Springer. Pp 11-44.

Warren, D. M. (1992). Indigenous knowledge, biodiversity conservation and development in Nairobi, Kenya. Journal international Conference on Conservation of Biodiversity in Africa. 2, 2-6. 